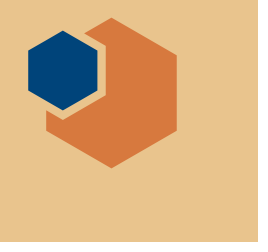

\title{
US stimulus bill includes funds for R\&D
}

$\mathrm{O}^{\prime}$ n Friday, March 12, 2021, President Joe Biden signed into law a \$1.9-trillion pandemic relief funding bill primarily designed to help US state and federal agencies combat the COVID-19 pandemic and assist in response efforts. Included in the legislation are funds to support research at the National Science Foundation and the National Institute of Standards and Technology.

In a news release, US Congressional Representative Eddie Bernice Johnson (D-Texas), said, “As Chairwoman of the House Committee on Science, Space, and Technology, I am also pleased that the American Rescue Plan directs funding through the National Science Foundation (NSF) and the National Institute of Standards and Technology (NIST) for vital research programs related to the prevention of, response to, and recovery from COVID-19."

"Our STEM [science-technologyengineering-mathematics] workforce has and will continue to play a significant role in combating the pandemic, and we must ensure that they have the resources necessary to continue their work," she added, according to the news release.
Specifically, \$600 million was allocated to NSF as a supplement to its budget and the agency was given a fair amount of latitude in terms of how that money could be spent. In regard to NIST, \$150 million was appropriated to help the agency strengthen its network of manufacturing institutes.

The legislation also includes over $\$ 1.7$ billion designed to help efforts to sequence and track variants of the COVID-19 virus.

Aside from the research funding, the bill provides $\$ 40$ billion in general relief for higher education institutions.

Damon Dozier

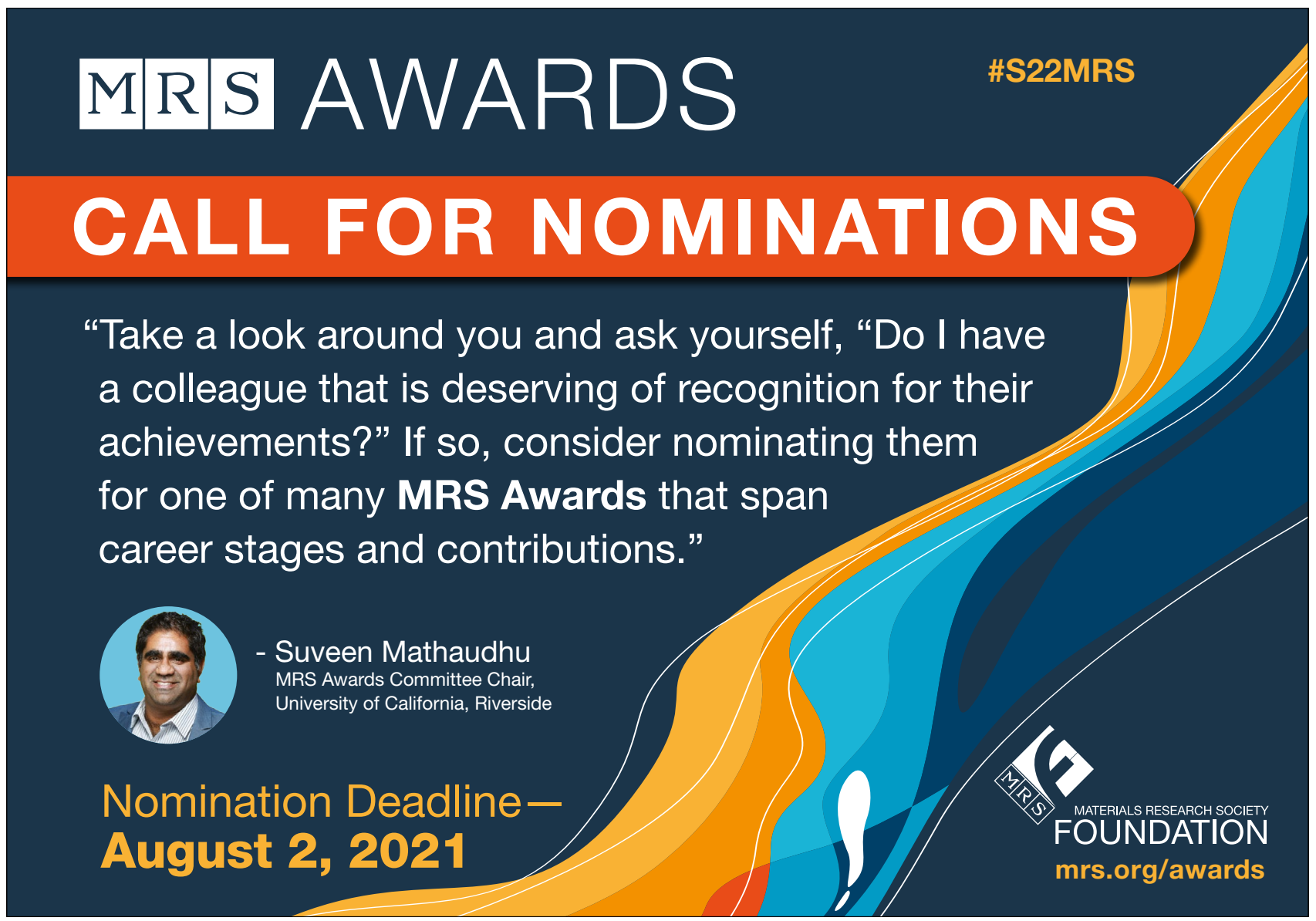

